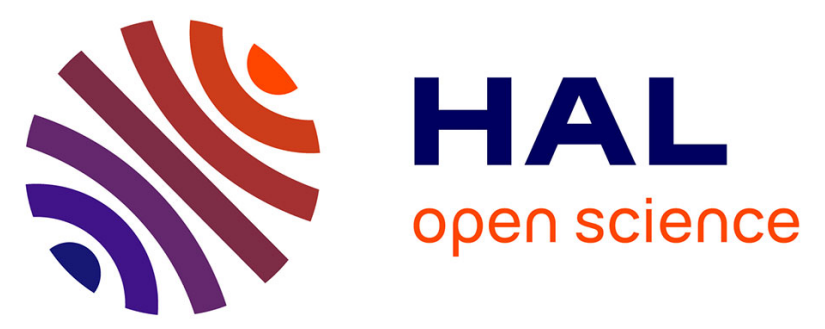

\title{
Socioeconomic inequalities in weight, height and body mass index from birth to 5 years
}

Morgane Ballon, Botton Jérémie, Marie Aline Charles, Sophie Carles, Blandine de Lauzon-Guillain, Anne Forhan, A. Cameron, Barbara Heude, Sandrine Lioret, Eden Mother-Child Cohort Study Group

\section{To cite this version:}

Morgane Ballon, Botton Jérémie, Marie Aline Charles, Sophie Carles, Blandine de Lauzon-Guillain, et al.. Socioeconomic inequalities in weight, height and body mass index from birth to 5 years. International Journal of Obesity, 2018, 42 (9), pp.1671-1679. 10.1038/s41366-018-0180-4 . hal-02898171

\section{HAL Id: hal-02898171 https://hal.inrae.fr/hal-02898171}

Submitted on 13 Jul 2020

HAL is a multi-disciplinary open access archive for the deposit and dissemination of scientific research documents, whether they are published or not. The documents may come from teaching and research institutions in France or abroad, or from public or private research centers.
L'archive ouverte pluridisciplinaire HAL, est destinée au dépôt et à la diffusion de documents scientifiques de niveau recherche, publiés ou non, émanant des établissements d'enseignement et de recherche français ou étrangers, des laboratoires publics ou privés. 
2 M Ballon $^{1,2^{*}}$, J Botton ${ }^{1,2,3}$, MA Charles ${ }^{1,2}$, S Carles ${ }^{1,2}$, B de Lauzon-Guillain ${ }^{1,2}$, A Forhan ${ }^{1,2}$, A

3 Cameron $^{4}$, B Heude ${ }^{1,2}$, S Lioret $^{1,2}$; on behalf of the EDEN mother-child cohort study group ${ }^{5}$

\section{Author affiliations}

$5 \quad{ }^{1}$ Paris Descartes University, Paris, France

${ }^{2}$ U1153 Epidemiology and Biostatistics Sorbonne Paris Cité Research Center (CRESS), Early

Origin of the Child's Health and Development Team (ORCHAD), Inserm, Villejuif, France

${ }^{3}$ Faculty of pharmacy, université Paris-Sud, université Paris-Saclay, 92296 ChâtenayMalabry, France

${ }^{4}$ Deakin University, Geelong, Australia. Global Obesity Centre, School of Health and Social Development.

${ }^{5}$ Members of the EDEN Mother-Child Cohort Study Group: I. Annesi-Maesano, J.Y. Bernard, J. Botton, M.A. Charles, P. Dargent-Molina, B. de Lauzon-Guillain, P. Ducimetière, M. de Agostini, B. Foliguet, A. Forhan, X. Fritel, A. Germa, V. Goua, R. Hankard, B. Heude, M. Kaminski, B. Larroque†, N. Lelong, J. Lepeule, G. Magnin, L. Marchand, C. Nabet, F Pierre, R. Slama, M.J. Saurel-Cubizolles, M. Schweitzer, O. Thiebaugeorges.

Short running title: Socioeconomic inequalities in early growth

Corresponding Author (and requests for reprints): Morgane Ballon, INSERM, UMR1153 Epidemiology and Biostatistics Sorbonne Paris Cité Center (CRESS), Early ORigin of the Child's Health And Development Team (ORCHAD), 16, avenue Paul Vaillant Couturier, 94807 Villejuif Cedex France. morgane.ballon@inserm.fr; +033145595178

\section{Conflict of interest}

None of the authors had a conflict of interest. 
Funding:

27 Support for the EDEN study (Étude des Déterminants pré- et postnatals précoces du développement et de la santé de l'ENfant) was provided by the following organizations: Fondation pour la Recherche Médicale, French Ministry of Research, Institut Fédératif de Recherche and Cohort Program, INSERM Nutrition Research Program, French Ministry of Health Perinatal Program, French Agency for Environment Security (AFFSET), French National Institute for Population Health Surveillance (INVS), Paris-Sud University, French National Institute for Health Education (INPES), Nestlé, Mutuelle Générale de l'Éducation Nationale, French Speaking Association for the Study of Diabetes and Metabolism (Alfediam), National Agency for Research (ANR nonthematic program), and National Institute for Research in Public Health (IRESP TGIR Cohorte Santé 2008 Program). The study sponsors were not involved in the study design, data collection, or data analyses.

Abbreviations: Body Mass Index (BMI); Ponderal Index (PI); Overweight (OW) 


\section{Abstract}

Background/Objectives: Studies in high income countries show that despite the positive association of weight with socioeconomic position at birth, an inverse socioeconomic gradient in overweight (OW) appears later in childhood. The objectives were to understand the natural history of socioeconomic inequalities in weight, height and body mass index (BMI), by investigating their associations with maternal educational level between birth and five years, separately in boys and girls.

Subjects/Methods: A published work of growth modelling between birth and 5 years allowed us to calculate predicted weight, height and BMI at 1 month, 6 months, 1, 3 and 5 years for 1735 children from the French EDEN mother-child cohort. Associations between maternal education and predicted measures of body size were analysed with marginal linear and logistic models, stratified by sex.

Results: In girls, despite a positive association between maternal education and birthweight, an inverse socioeconomic gradient was observed as early as 1 month for BMI. Girls whose mothers had low education levels were shorter on the whole than their counterparts with better-educated mothers, despite their similar weights. In boys, no socioeconomic gradient in BMI was observed at any age, including birth, but positive associations were found as early as 1 month for both weight and height.

Conclusion: The emergence of an inverse socioeconomic gradient in BMI and OW apparently results from a complex pattern of socioeconomic inequalities in weight and height from 1 month onwards. The very start of life thus appears to be an important window of opportunity for addressing socioeconomic inequalities in growth. 


\section{INTRODUCTION}

Childhood overweight (OW) and obesity are an important public health concern worldwide because of their relations to a range of short- and long-term health issues. ${ }^{1-3}$ Moreover, OW children are more likely to remain OW in adulthood. ${ }^{4}$ Childhood is therefore a critical window for preventing the development of excessive adiposity and its associated negative health outcomes, which are likely to accumulate across the life course.

The prevalence of OW in children has sharply increased worldwide since the 1970s, although evidence suggests that it has stabilized in some industrialized countries in recent years. ${ }^{5-9} \mathrm{An}$ inverse association between socioeconomic position and child adiposity has been identified, ${ }^{10}$ 11 and its gradient is reported to widen with age $\mathrm{e}^{12-14}$ as well as with time, since stronger gradients have been observed in more recent studies. ${ }^{15-17}$ This inverse socioeconomic gradient in the body mass index (BMI) of children seems paradoxical in view of the positive association between socioeconomic position and weight observed at birth. ${ }^{18,}{ }^{19}$ Given the switch from lower weight at birth to greater adiposity during childhood in more disadvantaged children, growth history from birth, including the effects of changes in weight and height or length on BMI gradient, is an interesting topic. Various studies have examined the age at which this inverse socioeconomic gradient in BMI or OW appears, with findings of around 4 years in England, ${ }^{13}$ before $4-5$ years in Australia, ${ }^{14}$ between 2 and 7 years in Germany ${ }^{20}$, before 7 years in Denmark ${ }^{21}$ and around 6 years in Holland. ${ }^{12,22}$ This gradient may operate differently according to sex, in view of the steeper socioeconomic inequalities in BMI and $\mathrm{OW}^{13,23,24}$ or in length ${ }^{25,26}$ that have been reported in girls. However, most of the studies that have explored the age of onset of the inverse socioeconomic gradient in BMI or OW are limited by both ages at data collection and the methods used, which do not take the non-linear shape of the BMI or z-score BMI growth trajectories into account accurately. 
In France, separate cross-sectional studies have demonstrated an inverse relation between socioeconomic position and $\mathrm{OW}$ at both $5-6$ years $^{27-29}$ and at 2 years. ${ }^{30}$ Given this background, we hypothesised that this inverse relation with socioeconomic position was likely to be apparent by 2 years of age. Our objectives were to understand the natural history of socioeconomic inequalities in weight, height and BMI, by investigating their associations with maternal education levels between birth and five years, separately in boys and girls.

\section{SUBJECTS AND METHODS}

\section{Study design and participants}

The EDEN mother-child cohort aimed to assess pre- and post-natal determinants of child growth, health and development. This cohort included 2002 pregnant women recruited in two maternity hospitals (in Poitiers and Nancy, France) between 2003 and 2006. Exclusion criteria were multiple gestation, known diabetes, illiteracy and intention to deliver outside the maternity hospitals or to move outside the region within 3 years. Details of the study protocol have been published elsewhere. ${ }^{31}$ Written consent was obtained from both parents. The study was approved by the ethics committee of Kremlin-Bicêtre and declared to the national commission for data protection and liberties (CNIL).

\section{Measurements}

Data were collected from obstetric and paediatric records at birth and then from self-reported questionnaires completed by the mothers and clinical examinations undertaken at different stages of follow-up.

\section{Socioeconomic position}

Maternal education was used as a proxy for socioeconomic position, as it is the indicator most consistently and strongly associated with child adiposity in the literature ${ }^{10}$ and is less likely to be affected by childbearing - unlike income and occupation. Mothers were asked to selfreport their highest educational attainment at inclusion. Educational level was categorized as 
low (failed to complete high school), intermediate (high school diploma to 2-year university degree, reference category) and high (3-year university degree or more).

\section{Weight and length or height}

Weight was measured by previously trained midwives at birth, 1 year, 3, and 5 years using an electronic scale (Seca Ltd or Terraillon SL-351). At 1 year, mothers were weighed both alone and holding the child, whose weight was obtained by subtracting the two measurements. Length was measured at birth and 1 year with a somatometer (Testut, NMMedical), and height at 3 and 5 years with a stadiometer (Seca Ltd). For simplicity's sake, height will be used to qualify length throughout the paper. Additionally, mothers filled in self-administered questionnaires at 4 months, 8 months and 1, 2, 3, 4 and 5 years. They were asked to report measured growth data available in their child's health booklet: one per month until one year, and two or three per year until five year. Of note, the latter were measured by primary care pediatricians or general practitioners during routine health monitoring.

\section{Preliminary statistical treatment of growth data}

Using all available collected data (on average 16 measurements per child, measured either by midwives or primary care pediatricians/general practitioners), predicted weight and height were calculated using previously modelled trajectories from the Jenss-Bayley model. ${ }^{32,} 33$ These trajectories were calculated in children with at least two measurements of weight (excluding birthweight) or two measurements of height. ${ }^{32,33}$ In total, we were able to predict weight and height between birth and 5 years for 1764 children. Predicted weight growth did not include birthweight because the model assumes a monotonic shape and infants normally lose weight immediately after birth. Instead, the minimum weight recorded during the first 4 days was used. Given that studies are not consistent regarding the use of either BMI or ponderal index (PI) to identify fat mass differences, ${ }^{34-36}$ we calculated both predicted BMI and PI as predicted weight $(\mathrm{kg})$ divided by predicted height $(\mathrm{m})$ squared and cubed, respectively. 
Predicted weight, height, BMI and PI were calculated at 1 month and 6 months to characterise early growth and at 1 year, 3 and 5 years to facilitate sensitivity analysis between predicted and collected data (the latter coming from either the clinical examinations or the health booklets). OW was defined at 2, 3, 4, and 5 years according to the International Obesity Task Force (IOTF) definition, which provides thresholds from 2 years onwards. ${ }^{37}$

\section{Other variables}

Gestational age and maternal age were reported at birth. Preterm birth (yes/no) was defined based on gestational age $<37$ weeks of gestation.

\section{Population studied}

Among the 1907 children included in the EDEN cohort, 143 were excluded because they had fewer than two weight or height measurements between birth and 5 years, and 29 more due to missing values for maternal education. The sample in this analysis thus includes 1735 children (838 girls and 897 boys).

\section{Statistical analysis}

Characteristics of the study population (namely, mother's age, child's weight, length, BMI, PI and preterm birth) were described at birth according to maternal education and sex. Chisquare tests and ANOVA analyses were used for statistical comparisons as appropriate.

Linear and logistic marginal models were used to investigate the association between maternal education and repeated BMI, PI, weight and height data from 1 month to 5 years and OW from 2 years to 5 years, respectively. Child age was included as a categorical variable, defined based on 5 values in the linear models (i.e., 1 month, 6 months, 1 year, 3 and 5 years) and 4 values in the logistic model (i.e., 2, 3, 4 and 5 years). An interaction term involving child age and maternal education was included in each model to allow the association 


$$
\mathrm{y}_{\mathrm{ij}}=\beta_{0}+\beta_{1} \times \mathrm{sex}_{\mathrm{i}}+\beta_{2} \times \text { centre }_{\mathrm{i}}+\beta_{3 \mathrm{j}} \times \mathrm{age}_{\mathrm{ij}}+\beta_{4 \mathrm{k}} \times \text { education }_{\mathrm{ik}}+
$$

$$
\beta_{5 \mathrm{jk}} \times \text { age }_{\mathrm{ij}} \times \mathrm{education}_{\mathrm{ik}}+\varepsilon_{\mathrm{ij}}
$$

A hypothesis underlying this model is that the pattern of association with age and education is the same for both sexes. To test specifically whether the educational level was associated with the different growth trajectories differently in boys and girls, we computed two nested models (2 and 3), described below. The difference between these two models was assessed and tested through the interaction terms $\operatorname{sex}_{\mathrm{i}} \times \mathrm{education}_{\mathrm{ik}}$ and $\operatorname{sex}_{\mathrm{i}} \times \mathrm{age}_{\mathrm{ij}} \times \mathrm{education}_{\mathrm{ik}}$.

$$
\mathrm{y}_{\mathrm{ij}}=\beta_{0}+\beta_{1} \times \text { sex }_{\mathrm{i}}+\beta_{2} \text { centre }_{\mathrm{i}}+\beta_{3 \mathrm{j}} \times \mathrm{age}_{\mathrm{ij}}+\beta_{4 \mathrm{k}} \text { xeducation }_{\mathrm{ik}}+
$$$$
\beta_{5 \mathrm{jk}} \times \text { age }_{\mathrm{ij}} \times \text { education }_{\mathrm{ik}}+\beta_{6 \mathrm{j}} \times \text { age }_{\mathrm{ij}} \times \mathrm{sex}_{\mathrm{i}}+\beta_{7 \mathrm{k}} \times \mathrm{sex}_{\mathrm{i}} \times \text { education }_{\mathrm{ik}}+
$$

$$
\beta_{8 \mathrm{jk}} \times \operatorname{sex}_{\mathrm{i}} \times \text { age }_{\mathrm{ij}} \times \mathrm{education}_{\mathrm{ik}}+\varepsilon_{\mathrm{ij}}
$$

$$
\mathrm{y}_{\mathrm{ij}}=\beta_{0}+\beta_{1} \times \text { sex }_{\mathrm{i}}+\beta_{2} \times \text { centre }_{\mathrm{i}}+\beta_{3 \mathrm{j}} \times \mathrm{age}_{\mathrm{ij}}+\beta_{4 \mathrm{k}} \text { xeducation }_{\mathrm{ik}}+\beta_{5 \mathrm{jk}} \times_{\text {age }_{\mathrm{ij}} \times \text { education }_{\mathrm{ik}}}+
$$

$$
\beta_{6 \mathrm{j}} \times \mathrm{age}_{\mathrm{ij}} \times \mathrm{sex}_{\mathrm{i}}+\varepsilon_{\mathrm{ij}}
$$

We compared models (2) and (3) using the likelihood ratio test, or the quasi-likelihood under the independence model criterion (QIC) for OW. Given that the tests were significant for 4 of the 5 outcomes, all analyses were stratified by sex. The choice of the best matrix of covariance of residuals, among the unstructured, autoregressive heterogeneous, Toeplitz and compound symmetry matrices, relied on the convergence of the model and the minimization of the Akaike Information Criterion (AIC) or the QIC. An unstructured matrix was chosen for models of all continuous outcomes, except for models of height in girls, where a Toeplitz 
In a first sensitivity analysis, we investigated the impact of the 29 missing data items for maternal educational level on the results. Because these data were unlikely to be missing at random, we reran the analyses with two imputed databases, one with all missing data set at the low level of education, and the other with all missing data set at the high level of education. In a second sensitivity analysis, we used the observed values of BMI, PI, weight, and height (in place of the predicted ones) and further adjusted for exact age at clinical examination.

The population included in the analysis was compared to the population not included using chi-square tests and ANOVA analyses as appropriate. All analyses were conducted with SASv9.3 (SAS, Cary, NC, US). Graphics were plotted with R software. The level for significance of two-sided test was set at $P \leq 0.05$.

\section{RESULTS}

\section{Population characteristics}

The more highly educated mothers were older than the less educated mothers (Table 1). Girls born to mothers with high educational levels had higher measured birth weights and birth lengths than girls whose mothers had low educational levels, while no significant difference was observed in boys. A trend towards a positive association between maternal education and BMI and PI at birth was observed in boys only $(P<0.10)$.

\section{Maternal education and BMI and PI}

In girls, an inverse socioeconomic gradient in BMI was observed from 1 month to 5 years (Figure 1). Consistent results were found with PI. In boys, the association between education and BMI changed along the age range in a non-monotonic fashion $(P$ for age $\times$ education interaction $=0.02$ ), but no significant socioeconomic gradient in BMI was observed at any age (Figure 1). A significant negative association was however observed with PI at 1 month and at 5 years (Supplementary Figure 1). 
206 At 2 years, the risk of OW in girls was already inversely associated with maternal education

207

(Figure 2). This inverse gradient was consistent across all ages studied, as reflected by the non-significant interaction between age and maternal education ( $\mathrm{P}$ for age $\times$ education interaction $=0.28$ ). In boys, the risk of OW did not differ according to maternal education from 2 to 5 years and there was no interaction between age and maternal education ( $\mathrm{P}$ for age $\times$ education interaction $=0.68$, Figure 2).

\section{Maternal education and weight}

Girls born to mothers with a low educational level had a lower birthweight (Table 1) but the pattern of the relation between maternal education and children's postnatal weight then seemed to shift. This change had already started at 1 month and was also observed at subsequent ages but we did not observe any significant gradient in weight at any age (Figure 3, $\mathrm{P}$ for age $\times$ education interaction $<0.01$ ). In boys, there was no significant gradient at birth or at 1 month, but a positive socioeconomic gradient in weight was observed between 6 months and 3 years. The change in the association across ages was reflected by the significance of the interaction test $(\mathrm{P}$ for age $\times$ education interaction $<0.01$, Figure 3 ).

\section{Maternal education and height}

Girls whose mothers had low educational levels were significantly shorter than their counterparts whose mothers had more education at birth, 1 month and 5 years (Figure 4). In boys, this association remained significant as early as 1 month through 5 years (Figure 4, $P$ for age $\times$ education interaction $=0.06$ for both girls and boys).

\section{Sensitivity analyses}

Results were on the whole consistent when analyses were performed on the databases with imputed maternal education as low or high (results not shown but available on request). When we used observed instead of predicted data, the overall pattern of the relations between 
maternal education and continuous outcomes (BMI, PI, weight or height) was consistent regarding effect size, in both sexes (results not shown but available on request).

\section{Comparison of included to excluded population}

Mothers excluded from the analysis $(n=172)$ were younger and less educated than those included (mean age (SD): 27.6 (5.3) vs. 29.7 (4.8) years; low education level: $52.2 \%$ vs. 26.9\%). The proportion of boys and preterm births was higher in children excluded from the analysis (boys: $61.3 \%$ vs. $51.7 \%$; preterm: $9.4 \%$ vs. $5.4 \%$ ). No significant difference was observed in length and weight measured at birth among those included and excluded respectively (length: $49.3(2.7)$ vs. $49.6(2.3) \mathrm{cm}$; weight: $3.23(0.57)$ vs. $3.28(0.51) \mathrm{kg})$.

\section{DISCUSSION}

Using a large French mother-child cohort with repeated measurements of height and weight on 1735 children between birth and 5 years, this study provides original and comprehensive insights into the socioeconomic patterning of $\mathrm{BMI}$ and $\mathrm{OW}$, in light of the socioeconomic inequalities in weight and height growth.

\section{BMI, PI and $O W$}

Our results show that, in girls, whereas birthweight was lower in newborns of women with low educational levels, an inverse socioeconomic gradient in BMI and PI was already visible at 1 month of age. Similarly, a socioeconomic gradient was observed for OW from 2 years, the earliest age for which cut-off points are available. Socioeconomic inequalities in BMI, OW and PI in girls were therefore observed even earlier than in previous studies. ${ }^{12,14,20-22,38}$ Although an inverse association with PI was observed in boys at 1 month and 5 years, we did not find any significant association between maternal education and their BMI or OW during the first 5 years of life.

Other studies have also suggested stronger or earlier associations between socioeconomic position and adiposity measures in girls compared to boys. Apouey et al. showed an inverse 
socioeconomic gradient in OW from 2-3 years in girls and only from 4-5 years in boys, ${ }^{24}$ while Howe et al. found an inverse socioeconomic gradient in BMI at 8 years and fat mass at 9 years in girls but nothing in boys. ${ }^{13,25}$ Differences in body composition between sexes have been described from infancy, ${ }^{36,39,40}$ with a higher proportion of BMI (or PI) variability explained by fat mass in girls. This relatively better reflection of body fat mass variability by BMI (or PI) in girls could partly explain the sex differences found in all these studies.

\section{Weight and height}

Socioeconomic gradients in weight and height were also observed very early in life. In girls, although weight did not differ according to maternal education from 1 month of age onwards, we observed that those born to mothers with low educational levels were shorter on the whole. This difference in height but not in weight seemed to drive the inverse socioeconomic gradient in both BMI and OW from 1 month and 2 years onwards, respectively. In boys, while height was related to maternal education at each age, the parallel positive relation between maternal education and weight meant that neither BMI nor OW varied according to maternal education at any age.

Although the emergence of socioeconomic inequalities in BMI across childhood has so far mainly been addressed with a focus on weight, our findings shed light on the potential importance of height in the early development of such disparities. Socioeconomic patterning of height in childhood was also observed by Howe et al. in the Avon Longitudinal Study of Parents and Children (ALSPAC), ${ }^{25,26}$ Finch et al. in US children ${ }^{41}$ and Matijasevich et al. in Brazilian children. ${ }^{42}$ This trend has not, however, been observed in all studies. ${ }^{43,44}$ Besides the methodological differences between studies (e.g. cross-sectional vs. longitudinal design, statistical models used, ages studied), discrepancies between findings could come from differences in the choice of the proxy of socioeconomic position or in the way that socioeconomic position affects weight-related behaviours in different populations. It is also 
possible that socioeconomic patterning of growth and BMI takes place earlier in life in the most recent generations, given the increase of adiposity ${ }^{3}$ and socioeconomic inequalities in recent decades. $^{45}$

\section{Potential explanations for socioeconomic inequalities in growth}

Although our focus was a description of the socioeconomic gradient in growth over time, it is worth considering the biological mechanisms that may underpin our findings. Weight and height may be transmitted across generations through both genetic and environmental influences. ${ }^{46-49}$ Smaller babies, exposed to an obesogenic environment, are perhaps more vulnerable to overconsumption (and thus energy imbalance), than their taller counterparts. It has also been suggested that babies born in disadvantaged backgrounds are more often exposed to suboptimal parental feeding styles. In particular, mothers of smaller infants are more likely to use pressuring styles, which could also contribute to overfeeding. ${ }^{50}$ There is also evidence showing a positive socioeconomic gradient in breastfeeding at the population level in industrialized countries, ${ }^{51}$ along with a slower growth during the first year of life in breastfed babies ${ }^{52}$ and lower risk for overweight or obesity later in childhood. ${ }^{53}$ Overall, suboptimal health, diet and growth from birth could be considered to be indicators of a more global vulnerability transmitted from the mother to the child.

Our results add to the evidence that socioeconomic inequalities take root before birth, before and during pregnancy, and continue into childhood. In the background of this intergenerational transmission of inequality, our findings confirm that the window of opportunity for combatting non-optimal growth and/or OW begins very early in life. Future research into the early and modifiable risk factors involved in the socioeconomic patterning of both height and weight growth in girls and boys is clearly a priority.

\section{Limitations and strengths}


Limitations of the study include the fact that the predicted data were based on a mixture of measured data and data collected from health booklets. The latter, likely more subject to measurement errors, may have affected the accuracy of the predicted data and decreased the statistical power. Modelling was performed on the assumption that children lost to follow-up had experienced the same growth curve compared to children with a complete follow-up and a similar initial growth. This hypothesis, although possible, could not be verified, and we cannot be certain of the validity of the growth modelling of children who dropped out. In addition, prevalence of OW at 5 years was rather low in the Eden cohort, especially in boys (5.7\% vs. $9.8 \%$ in girls), ${ }^{54}$ compared to findings from the $2006-07$ INCA2 national dietary survey, which reported a prevalence of $13.5 \%$ in children aged 3-6 years. ${ }^{55}$ The presence of selection bias at inclusion, as is often the case in cohort studies, is therefore possible and may have implications for generalisation of the findings. Specifically, only including literate women at baseline may have resulted in an underrepresentation of disadvantaged families, which might have weakened our ability to compare mothers according to their education level. We also acknowledge that, consistent with the literature, we used maternal education level as a proxy for socioeconomic position. Given the complexity in accurately assessing socioeconomic position, we cannot be certain that the results relating to disadvantage in our analysis would not change if a different indicator were used. It is also possible that BMI is not the most appropriate indicator of adiposity as it has been shown to underestimate the socioeconomic gradient in obesity and body fatness. ${ }^{56,57}$ Under these circumstances, however, our findings, which suggest early socioeconomic inequalities in weight, height and BMI even in this rather low-risk sample, make the public health arguments even stronger. A clear strength of our study is that data are from a birth cohort, making it possible to address the link between maternal education and the various outcomes prospectively, using marginal models to account for repeated measurements. Growth modelling was the preferred method as 
it allowed us to estimate accurate predicted weight and height at any age despite measurement error and missing values across the follow-up and thus reducing mis-classification and attrition biases.

In conclusion, these findings showed that the emergence of an inverse socioeconomic gradient in BMI and OW apparently results from a complex pattern of socioeconomic inequalities of weight and height from 1 month onwards. The very start of life thus appears to be an important window of opportunity for addressing socioeconomic inequalities in growth.

Acknowledgements: We are extremely grateful to all the families who took part in this study, the midwives and psychologists who recruited and followed them, and the whole EDEN team, including research scientists, engineers, technicians and managers and especially Josiane Sahuquillo and Edith Lesieux for their commitment and their role in the success of the study. We also acknowledge the commitment of the members of the EDEN Mother-Child Cohort Study Group: I. Annesi-Maesano, J.Y. Bernard, J. Botton, M.A. Charles, P. Dargent-Molina, B. de Lauzon-Guillain, P. Ducimetière, M. de Agostini, B. Foliguet, A. Forhan, X. Fritel, A. Germa, V. Goua, R. Hankard, B. Heude, M. Kaminski, B. Larroque†, N. Lelong, J. Lepeule, G. Magnin, L. Marchand, C. Nabet, F Pierre, R. Slama, M.J. Saurel-Cubizolles, M. Schweitzer, O. Thiebaugeorges. We thank Jo Ann Cahn for her help in preparing the manuscript.

Contributors: $\mathrm{MB}, \mathrm{SL}, \mathrm{BH}$ and JB conceived and designed the work, with advice from MAC. MB analyzed the data with advice from BH, JB and SL. MB, BH and SL drafted and revised the manuscript. All authors interpreted the data and criticized the manuscript for important intellectual content. MAC and BH designed and led the EDEN mother-child cohort. 
$354 \mathrm{AF}$ is responsible for the EDEN data management. JB and SC have fitted weight and height 355 growth trajectories using the Jenss-Bayley nonlinear model and provided the relevant data. 356 All authors have read and approved the final version of the manuscript. This article is the 357 work of the authors. MB serves as guarantor for the contents of this article. All authors had 358 full access to all of the data (including statistical reports and tables) in the study and take the 359 responsibility for the integrity of the data and the accuracy of the data analysis. All 360 researchers are independent of the funding bodies. All members in the EDEN mother-child 361 cohort study group designed the study and revised the draft manuscript. 
1. Pulgaron ER. Childhood obesity: a review of increased risk for physical and psychological comorbidities. Clin Ther 2013;35:A18-32.

2. Reilly JJ, Kelly J. Long-term impact of overweight and obesity in childhood and adolescence on morbidity and premature mortality in adulthood: systematic review. Int $J$ Obes (Lond) 2011;35:891-8.

368 3. Williams EP, Mesidor M, Winters K, Dubbert PM, Wyatt SB. Overweight and Obesity: Prevalence, Consequences, and Causes of a Growing Public Health Problem. Curr Obes Rep 2015;4:363-70.

4. Simmonds M, Llewellyn A, Owen CG, Woolacott N. Predicting adult obesity from childhood obesity: a systematic review and meta-analysis. Obes Rev 2016;17:95-107.

5. Ahluwalia N, Dalmasso P, Rasmussen M, Lipsky L, Currie C, Haug E, et al. Trends in overweight prevalence among 11-, 13- and 15-year-olds in 25 countries in Europe, Canada and USA from 2002 to 2010. Eur J Public Health 2015;25 Suppl 2:28-32.

6. Olds T, Maher C, Zumin S, Peneau S, Lioret S, Castetbon K, et al. Evidence that the prevalence of childhood overweight is plateauing: data from nine countries. Int J Pediatr Obes 2011;6:342-60.

7. Wabitsch M, Moss A, Kromeyer-Hauschild K. Unexpected plateauing of childhood obesity rates in developed countries. BMC Med 2014;12:17.

8. Wang Y, Lobstein T. Worldwide trends in childhood overweight and obesity. Int J Pediatr Obes 2006;1:11-25.

9. Verdot C TM, Salanave B, Deschamps V. Corpulence des enfants et des adultes en France métropolitaine en 2015. Résultats de l'étude Esteban et évolution depuis 2006. Bull Epidémiol Hebd 2017;13:234-41.

10. Shrewsbury V, Wardle J. Socioeconomic status and adiposity in childhood: a systematic review of cross-sectional studies 1990-2005. Obesity (Silver Spring) 2008;16:275-84.

11. Ruiz M, Goldblatt P, Morrison J, Porta D, Forastiere F, Hryhorczuk D, et al. Impact of Low Maternal Education on Early Childhood Overweight and Obesity in Europe. Paediatr Perinat Epidemiol 2016;30:274-84.

12. Bouthoorn SH, Wijtzes Al, Jaddoe VW, Hofman A, Raat H, van Lenthe FJ. Development of socioeconomic inequalities in obesity among Dutch pre-school and school-aged children. Obesity (Silver Spring) 2014;22:2230-7.

13. Howe LD, Tilling K, Galobardes B, Smith GD, Ness AR, Lawlor DA. Socioeconomic disparities in trajectories of adiposity across childhood. Int J Pediatr Obes 2011;6:e144-53.

14. Jansen PW, Mensah FK, Nicholson JM, Wake M. Family and neighbourhood socioeconomic inequalities in childhood trajectories of BMI and overweight: longitudinal study of Australian children. PLoS One 2013;8:e69676.

15. Guignon N, Herbet J, Fonteneau L, Guthmann J. La santé des enfants scolarisés en CM2 en 2004-2005. Premiers résultats Etudes et résultats (DRESS) 2008;632:1-8.

16. Chung A, Backholer K, Wong E, Palermo C, Keating C, Peeters A. Trends in child and adolescent obesity prevalence in economically advanced countries according to socioeconomic position: a systematic review. Obes Rev 2016;17:276-95.

17. Stamatakis E, Wardle J, Cole TJ. Childhood obesity and overweight prevalence trends in England: evidence for growing socioeconomic disparities. Int J Obes (Lond) 2010;34:41-7.

18. Cameron AJ, Spence AC, Laws R, Hesketh KD, Lioret S, Campbell KJ. A Review of the Relationship Between Socioeconomic Position and the Early-Life Predictors of Obesity. Curr Obes Rep 2015;4:350-62.

19. Ruiz M, Goldblatt P, Morrison J, Kukla L, Svancara J, Riitta-Jarvelin M, et al. Mother's education and the risk of preterm and small for gestational age birth: a DRIVERS meta-analysis of 12 European cohorts. J Epidemiol Community Health 2015;69:826-33. 

weight of German children reverse direction between the ages of 2 and 6 years. J Nutr 2003;133:78996.

21. Morgen CS, Andersen PK, Mortensen LH, Howe LD, Rasmussen M, Due P, et al. Socioeconomic disparities in birth weight and body mass index during infancy through age 7 years: a study within the Danish National Birth Cohort. BMJ Open 2017;7:e011781. 22. Ruijsbroek A, Wijga AH, Kerkhof M, Koppelman GH, Smit HA, Droomers M. The development of socio-economic health differences in childhood: results of the Dutch longitudinal PIAMA birth cohort. BMC Public Health 2011;11:225. 23. Balistreri KS, Van Hook J. Trajectories of overweight among US school children: a focus on social and economic characteristics. Matern Child Health J 2011;15:610-9.

24. Apouey BH. Child physical development in the UK: the imprint of time and socioeconomic status. Public Health 2016;141:255-63. behaviours and academic achievement across childhood and adolescence. $J$ Epidemiol Community Health 2013;67:358-64.

26. Howe LD, Tilling K, Galobardes B, Smith GD, Gunnell D, Lawlor DA. Socioeconomic differences in childhood growth trajectories: at what age do height inequalities emerge? J Epidemiol Community Health 2012;66:143-8.

27. Chardon O, Guignon N, De Saint Pol T. La santé des élèves de grande section de maternelle en 2013 : des inégalités sociales dès le plus jeune âge. Etudes et résultats (DRESS) 2015;920:1-6.

28. Lioret S, Maire B, Volatier JL, Charles MA. Child overweight in France and its relationship with physical activity, sedentary behaviour and socioeconomic status. Eur J Clin Nutr 2007;61:509-16. 29. Thibault H, Carriere C, Langevin C, Barberger-Gateau P, Maurice S. Evolution of overweight prevalence among 5-6-year-old children according to socio-economic status. Acta Paediatr 2013;102:273-7.

30. Apouey BH, Geoffard PY. Parents' education and child body weight in France: The trajectory of the gradient in the early years. Econ Hum Biol 2016;20:70-89.

31. Heude B, Forhan A, Slama R, Douhaud L, Bedel S, Saurel-Cubizolles MJ, et al. Cohort Profile: The EDEN mother-child cohort on the prenatal and early postnatal determinants of child health and development. Int J Epidemiol 2016;45:353-63.

32. Botton J, Scherdel P, Regnault N, Heude B, Charles MA, Group EM-CCS. Postnatal weight and height growth modeling and prediction of body mass index as a function of time for the study of growth determinants. Ann Nutr Metab 2014;65:156-66.

33. Carles S, Charles MA, Forhan A, Slama R, Heude B, Botton J, et al. A Novel Method to Describe Early Offspring Body Mass Index (BMI) Trajectories and to Study Its Determinants. PLoS One 2016;11:e0157766.

34. De Cunto A, Paviotti G, Ronfani L, Travan L, Bua J, Cont G, et al. Can body mass index accurately predict adiposity in newborns? Arch Dis Child Fetal Neonatal Ed 2014;99:F238-9.

35. Peterson CM, Su H, Thomas DM, Heo M, Golnabi AH, Pietrobelli A, et al. Tri-Ponderal Mass Index vs Body Mass Index in Estimating Body Fat During Adolescence. JAMA Pediatr 2017;171:62936.

36. Villar J, Puglia FA, Fenton TR, Cheikh Ismail L, Staines-Urias E, Giuliani F, et al. Body composition at birth and its relationship with neonatal anthropometric ratios: the newborn body composition study of the INTERGROWTH-21st project. Pediatr Res 2017;82:305-16.

37. Cole TJ, Flegal KM, Nicholls D, Jackson AA. Body mass index cut offs to define thinness in children and adolescents: international survey. BMJ 2007;335:194.

38. Gibbs BG, Forste R. Socioeconomic status, infant feeding practices and early childhood obesity. Pediatr Obes 2014;9:135-46.

39. Botton J, Heude B, Maccario J, Ducimetiere P, Charles MA, Group FS. Postnatal weight and height growth velocities at different ages between birth and $5 \mathrm{y}$ and body composition in adolescent boys and girls. Am J Clin Nutr 2008;87:1760-8. 
40. Fields DA, Gilchrist JM, Catalano PM, Gianni ML, Roggero PM, Mosca F. Longitudinal body composition data in exclusively breast-fed infants: a multicenter study. Obesity (Silver Spring) 2011;19:1887-91.

41. Finch BK, Beck AN. Socio-economic status and z-score standardized height-for-age of U.S.born children (ages 2-6). Econ Hum Biol 2011;9:272-6.

42. Matijasevich A, Howe LD, Tilling K, Santos IS, Barros AJ, Lawlor DA. Maternal education inequalities in height growth rates in early childhood: 2004 Pelotas birth cohort study. Paediatr Perinat Epidemiol 2012;26:236-49.

43. Herngreen WP, van Buuren S, van Wieringen JC, Reerink JD, Verloove-Vanhorick SP, Ruys JH. Growth in length and weight from birth to 2 years of a representative sample of Netherlands children (born in 1988-89) related to socioeconomic status and other background characteristics. Ann Hum Biol 1994;21:449-63.

44. van Rossem L, Silva LM, Hokken-Koelega A, Arends LR, Moll HA, Jaddoe VW, et al. Socioeconomic status is not inversely associated with overweight in preschool children. $J$ Pediatr 2010;157:929-35 e1.

45. OECD. Growing unequal? : Income Distribution and Poverty in OECD Countries. OECD Publishing, Paris 2008.

46. Aizer A, Currie J. The intergenerational transmission of inequality: maternal disadvantage and health at birth. Science 2014;344:856-61.

47. Barker D, Barker M, Fleming T, Lampl M. Developmental biology: Support mothers to secure future public health. Nature 2013;504:209-11.

48. Heude B, Kettaneh A, Rakotovao R, Bresson JL, Borys JM, Ducimetiere P, et al. Anthropometric relationships between parents and children throughout childhood: the FleurbaixLaventie Ville Sante Study. Int J Obes (Lond) 2005;29:1222-9.

49. Regnault N, Botton J, Forhan A, Hankard R, Thiebaugeorges O, Hillier TA, et al. Determinants of early ponderal and statural growth in full-term infants in the EDEN mother-child cohort study. Am J Clin Nutr 2010;92:594-602.

50. Thompson AL, Adair LS, Bentley ME. Pressuring and restrictive feeding styles influence infant feeding and size among a low-income African-American sample. Obesity (Silver Spring) 2013;21:56271.

51. Dennis CL. Breastfeeding initiation and duration: a 1990-2000 literature review. J Obstet Gynecol Neonatal Nurs 2002;31:12-32.

52. Betoko A, Lioret S, Heude B, Hankard R, Carles S, Forhan A, et al. Influence of infant feeding patterns over the first year of life on growth from birth to 5 years. Pediatr Obes 2017;12 Suppl 1:94101.

53. Horta BL, Loret de Mola C, Victora CG. Long-term consequences of breastfeeding on cholesterol, obesity, systolic blood pressure and type 2 diabetes: a systematic review and metaanalysis. Acta Paediatr 2015;104:30-7.

54. Saldanha-Gomes C, Heude B, Charles MA, de Lauzon-Guillain B, Botton J, Carles S, et al. Prospective associations between energy balance-related behaviors at 2 years of age and subsequent adiposity: the EDEN mother-child cohort. Int J Obes (Lond) 2017;41:38-45.

55. Lioret S, Touvier M, Dubuisson C, Dufour A, Calamassi-Tran G, Lafay L, et al. Trends in child overweight rates and energy intake in France from 1999 to 2007: relationships with socioeconomic status. Obesity (Silver Spring) 2009;17:1092-100.

56. Samani-Radia D, McCarthy HD. Comparison of children's body fatness between two contrasting income groups: contribution of height difference. Int J Obes (Lond) 2011;35:128-33. 57. van den Berg G, van Eijsden M, Vrijkotte TG, Gemke RJ. BMI may underestimate the socioeconomic gradient in true obesity. Pediatr Obes 2013;8:e37-40. 
BMI in girls

514

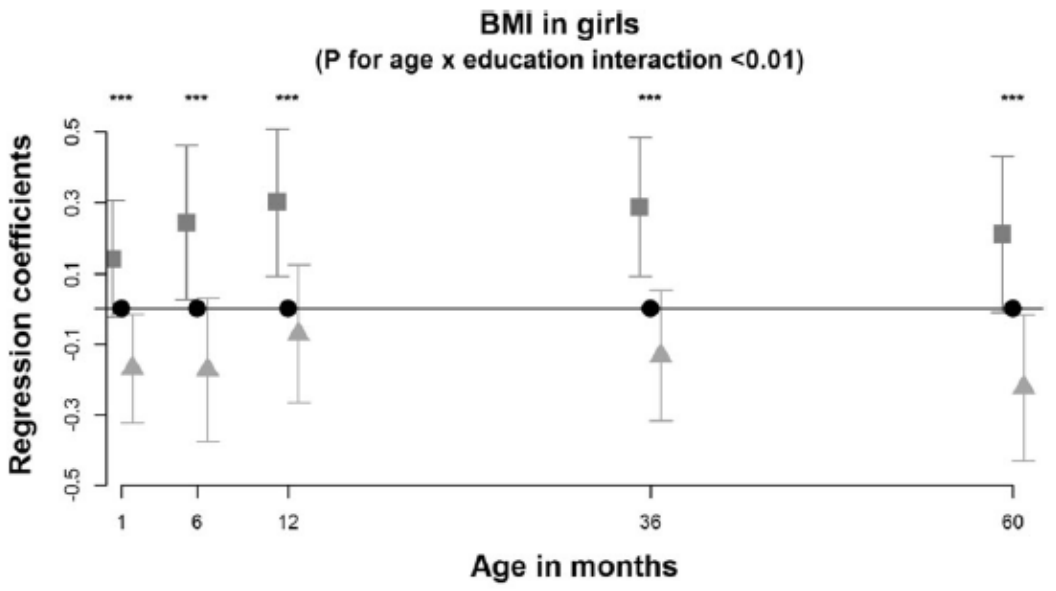

519

BMI in boys

( $P$ for age $x$ education interaction $=0.02$ )

520

521

522

523

524

525

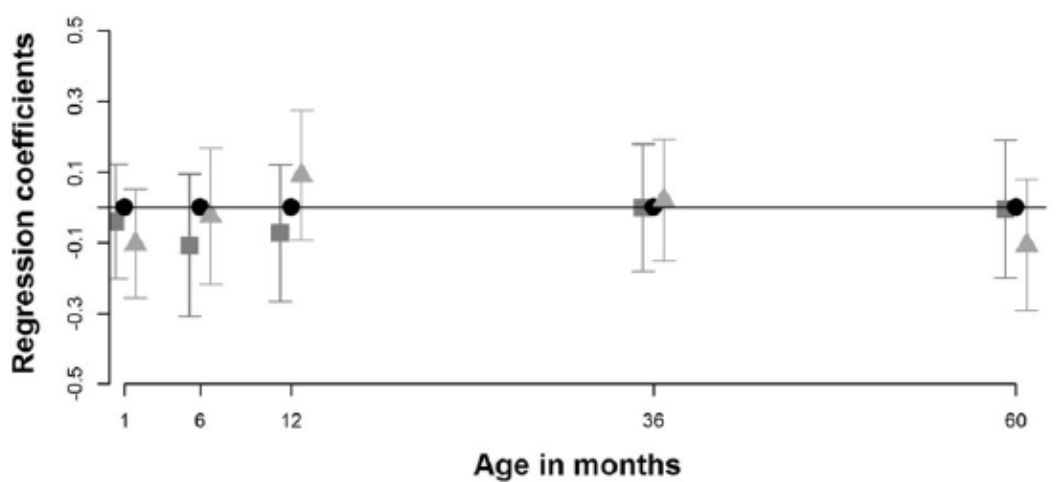

526

527

Maternal educational level :

Significance :

- Low

- Intermediate (ref)

* $\mathrm{P}<0.05$

A High

** $P<0.01$

*** $P<0.001$

528

529 Figure 1: Linear regression coefficients $[95 \% \mathrm{CI}]$ for association between maternal education and BMI,

530 adjusted for centre, in girls $(\mathrm{n}=838)$ and in boys $(\mathrm{n}=897)$. $P$ for sex interaction $<0.05$.

531

532

533

534

535 


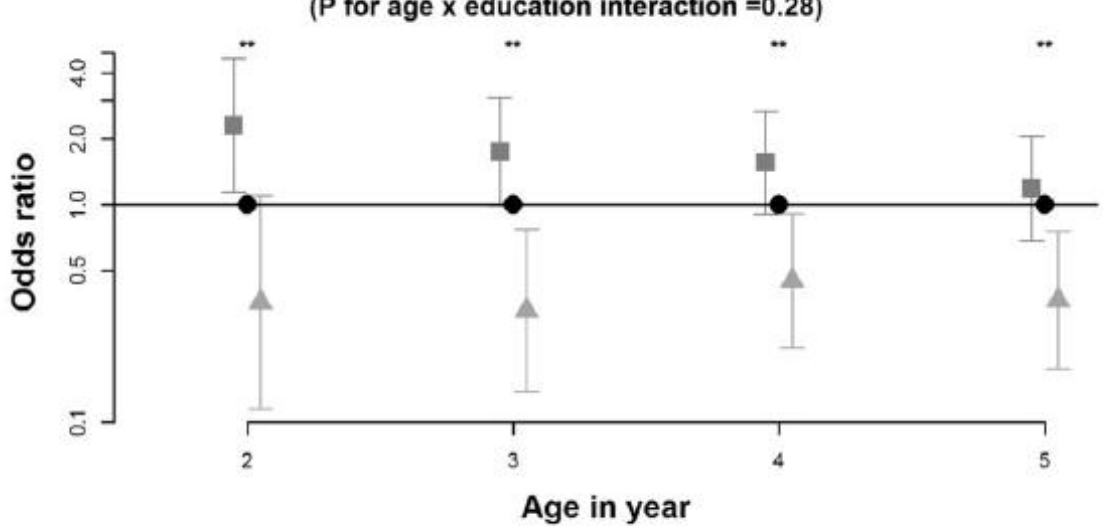

541

OW in boys

( $P$ for age $x$ education interaction $=0.68$ )

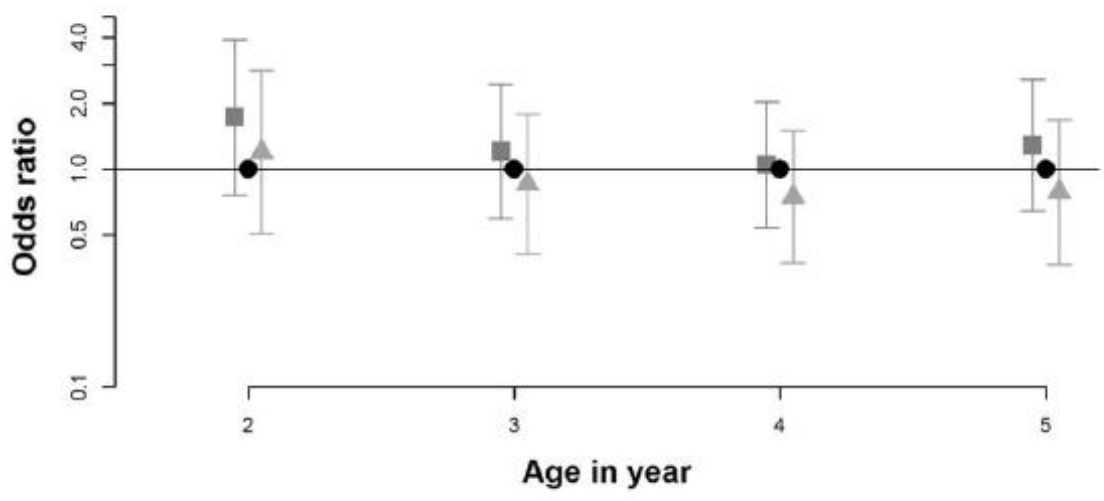

546

Significance :

" Low

- Intermediate (ref)

$\triangle$ High
* $P<0.05$

** $P<0.01$

*** $P<0.001$

548

549 Figure 2: Logistic regression coefficients [95\% CI] for association between maternal education and 550 overweight, adjusted for centre, in girls $(\mathrm{n}=838)$ and in boys $(\mathrm{n}=897) . P$ for sex interaction $<0.05$. 

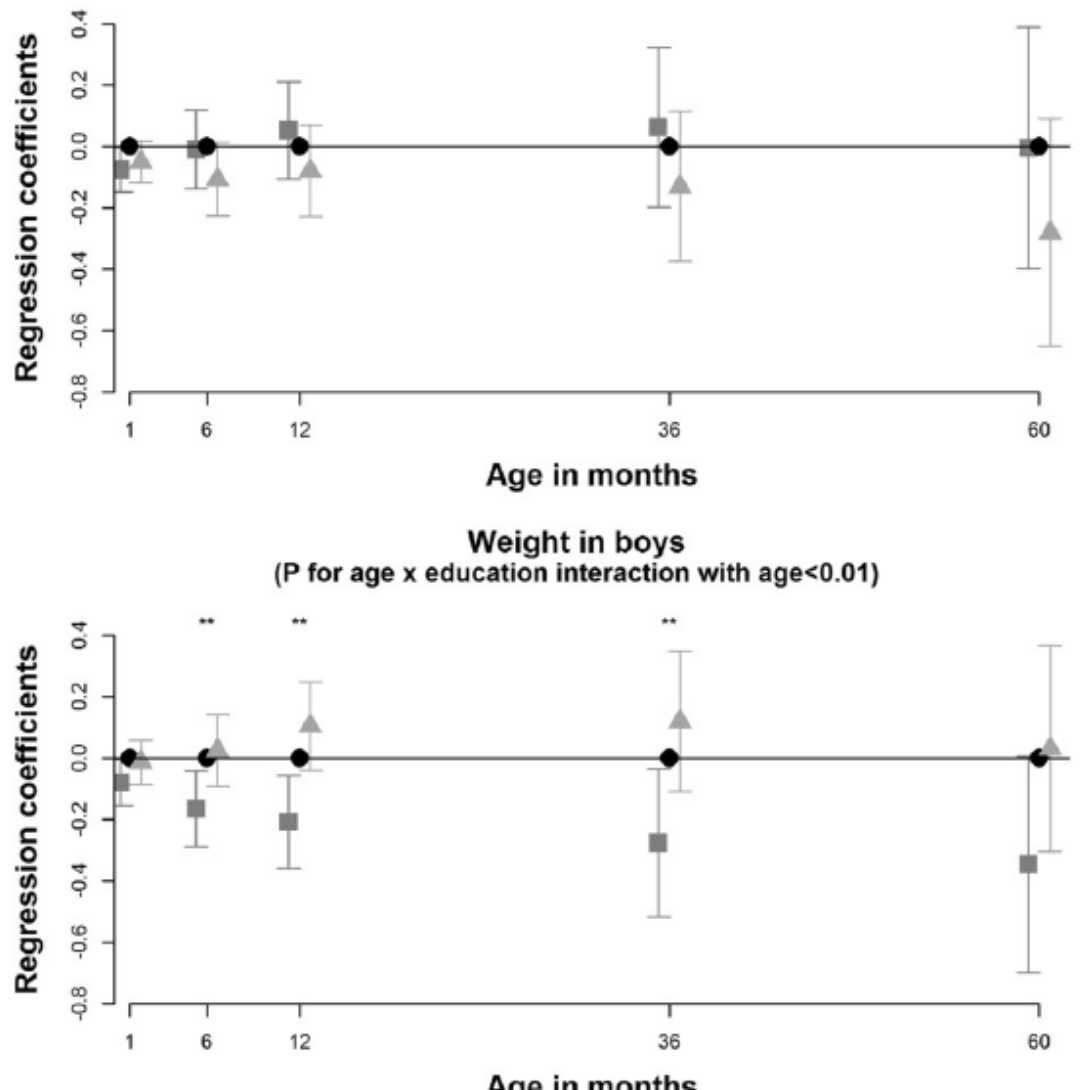

566

569 Figure 3: Linear regression coefficients $[95 \% \mathrm{CI}]$ for association between maternal education and 


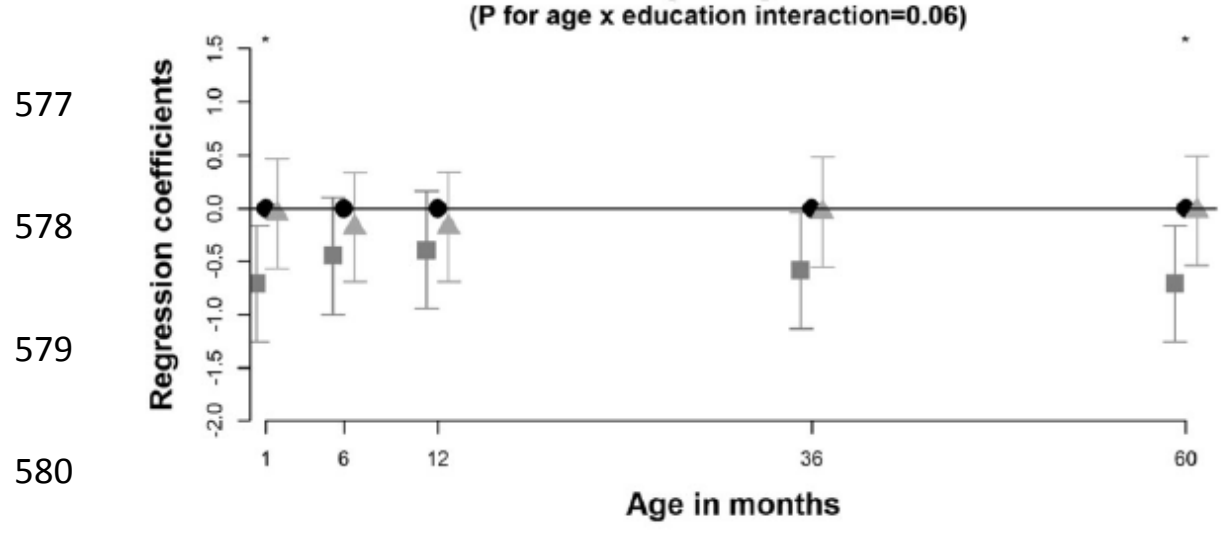

581

Height in boys

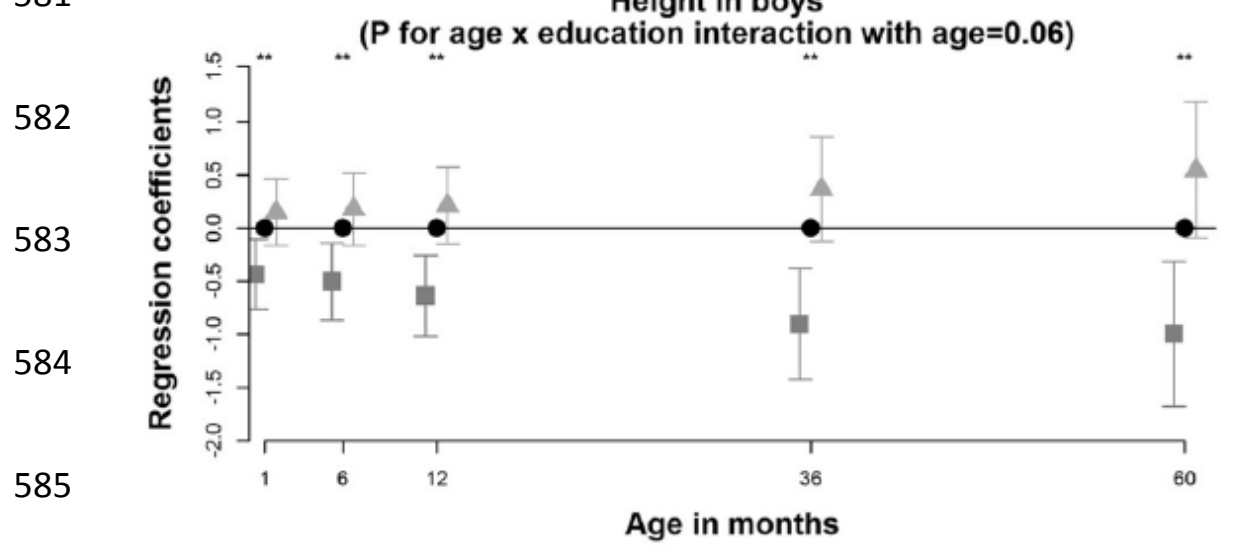

586

Significance :

- Low

* $P<0.05$

- Intermediate (ref)

$\Delta$ High

** $P<0.01$

*** $P<0.001$

588

589 Figure 4: Linear regression coefficients [95\%CI] for association between maternal education and

590 height, adjusted for centre, in girls $(n=838)$ and in boys $(n=897)$. $P$ for sex interaction $>0.05$. 